\title{
Plasma exchange: an option for the treatment of life-threatening status asthmaticus in pregnancy
}

\section{To the Editor:}

Status asthmaticus during pregnancy is a rare but lifethreatening condition for the mother and foetus. Some authors favour the termination of pregnancy by caesarean section, while others have succeeded in saving the life of both the mother and the baby by the use of artificial ventilation in addition to conventional drug therapy. We report our experience with a rather unusual approach for the treatment of drug-resistant status asthmaticus with respiratory failure in a 37-yr-old pregnant female.

Following many years of stable allergic seasonal asthma, the patient experienced a severe asthmatic attack following a positive pregnancy test at home. The emergency was overcome by i.v. corticosteroids $(250 \mathrm{mg})$ and theophylline $(200 \mathrm{mg})$. When the pregnancy with a gestational age of 13 weeks was confirmed by an obstetrician 3 days later, the patient experienced a relapse of her asthma and was admitted to her community hospital in severe respiratory distress. Her respiratory condition deteriorated despite immediate treatment using high doses of selective $\beta_{2}$-agonists and anticholinergic compounds, i.v. theophylline, corticosteroids and sodium bicarbonate. $\mathrm{Ob}-$ vious physical exhaustion, signs of hyperventilation and respiratory acidosis (arterial oxygen tension $\left(\mathrm{Pa}, \mathrm{O}_{2}\right)=11.6$ $\mathrm{kPa}(87 \mathrm{mmHg})$, arterial carbon dioxide tension $\left(\mathrm{Pa}, \mathrm{CO}_{2}\right)$ $=9.2 \mathrm{kPa}(69 \mathrm{mmHg})$, standard bicarbonate $=25 \mathrm{mval} \cdot \mathrm{L}^{-1}$, base excess $=2.9 \mathrm{mval} \cdot \mathrm{L}^{-1}, \mathrm{pH}=7.24$, respiratory frequency 35 breaths $\cdot \mathrm{min}^{-1}$ ) necessitated orotracheal intubation and artificial ventilation on the day after admission (day 2) (fig. 1). Despite profound sedation, muscle relaxation and repetitive bronchial lavage, the respiratory situation did not stabilize. The following selected drugs given to the patient (weight $=52 \mathrm{~kg}$ ) on this $3 \mathrm{rd}$ day after admission (May 14th) illustrate her outstanding drug requirements: ketamine 2,330 mg. day ${ }^{-1}$, diazepam $160 \mathrm{mg} \cdot$ day $^{-1}$, pancuronium $72 \mathrm{mg} \cdot \mathrm{day}^{-1}$, prednisone $2 \mathrm{~g} \cdot \mathrm{day}^{-1}$, reproterol $0.45 \mathrm{mg} \cdot$ day $^{-1}$, theophylline $1.7 \mathrm{~g} \cdot \mathrm{day}^{-\mathrm{P}}$ and clemastin 11 $\mathrm{mg} \cdot \mathrm{day}^{-1}$. After counselling with an obstetrician, an anaesthesiologist, a neonatologist and the patient's husband, a decision was made to give the patient every possible treatment irrespective of the baby's fate.

Although $\mathrm{Pa}, \mathrm{O}_{2}$ had stabilized above normal, $P \mathrm{a}, \mathrm{CO}_{2}$ continued to be elevated and varied according to the state of sedation or relaxation. Of particular concern were the progressively increasing inspiratory pressures required to maintain the tidal volume. On the 3rd day of the ongoing status asthmaticus, it was decided to apply plasma exchange as an ultimate therapeutic regimen (fig. 1). Based on theoretical grounds, our previous unpublished experience and anecdotal reports $[1,2]$, we attempted to eliminate circulating antigens and/or immunoglobulin E (IgE) which were supposed to be responsible for the sustained asthmatic response. Informed consent was obtained from the patient's husband. Matching with the estimated blood volume $(2.95 \mathrm{~L})$, on each of the 3 consecutive days, 3-3.5 L of plasma was exchanged via a double-lumen Sheldon catheter inserted in the right femoral vein. No technical or clinical complications occurred with these procedures.

Immediately after the first plasma exchange (day 3 ) the patient's clinical and respiratory function improved. The inspiratory pressures decreased dramatically, resulting in an increase in minute volume and concomitant drop in $\mathrm{Pa}_{\mathrm{a}} \mathrm{CO}_{2}$ (fig. 1). However, there were additional benefits,

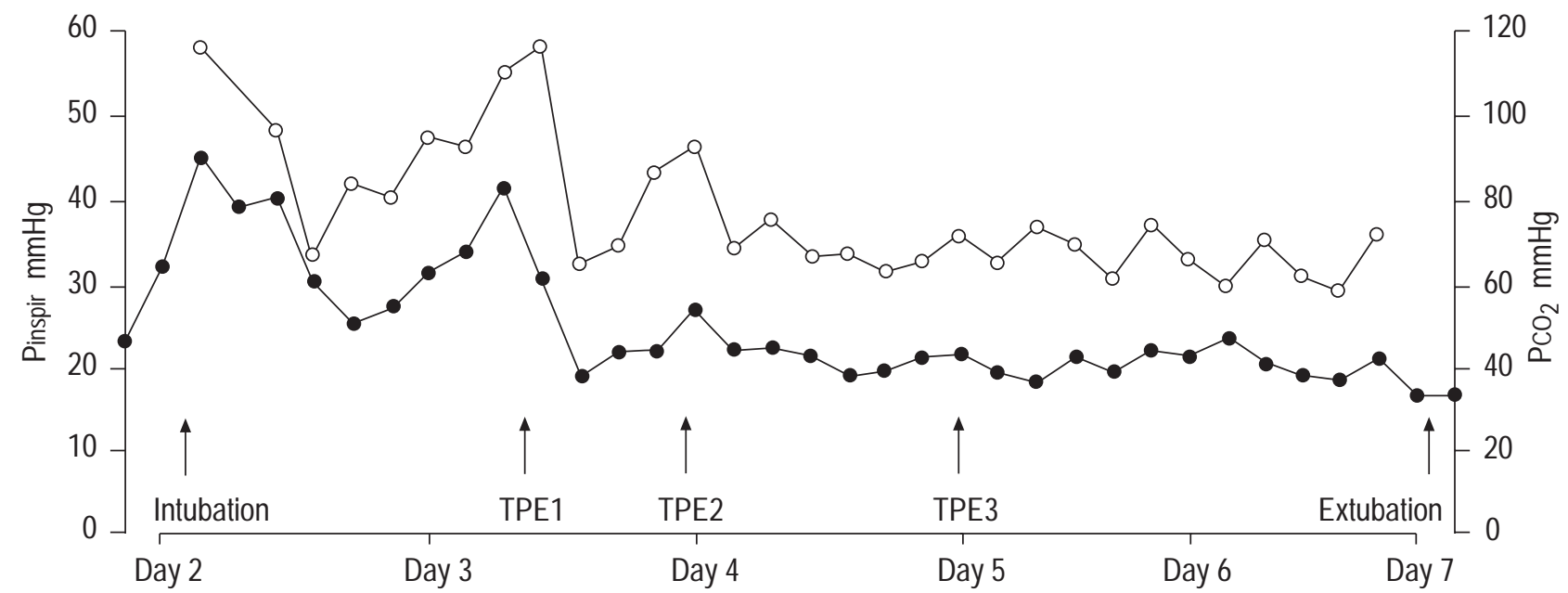

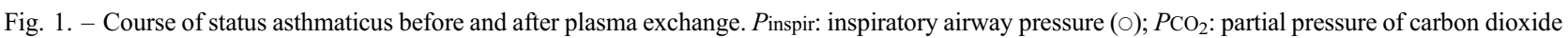
$(\bullet)$; TPE: therapeutic plasma exchange. 
particularly clinical after the second and third procedures. After a weaning period using inspiratory flow assistance the patient extubated herself on May 18 at 04:00 h. Auscultation revealed only minimal remaining wheeze. Her arterial blood gases at 05:00 h were: $P \mathrm{a}_{2} \mathrm{O}_{2}=13.1 \mathrm{kPa}(98.8$ $\mathrm{mmHg}), P \mathrm{a}, \mathrm{CO}_{2}=5.2 \mathrm{kPa}(39.2 \mathrm{mmHg})$, standard bicarbonate $=24.9 \mathrm{mval} \cdot \mathrm{L}^{-1}$, base excess $=1.3 \mathrm{mval} \cdot \mathrm{L}^{-1}, \mathrm{pH}=7.42$.

Following a period of mental depression and intermittent confabulation the patient finally recovered. There were no more asthmatic attacks throughout the remainder of the pregnancy. No other gestational complications such as hypertension, proteinuria or oedema formation ensued. Intensive evaluation of the foetal state in utero revealed an intact pregnancy. Amniocentesis was performed on May 31 (17th gestational week) and revealed a normal female karyostatus. On October 22 (37th week of gestation) the patient delivered a healthy daughter. Three years later we contacted the patient and her daughter again. She had not experienced another status asthmaticus but had had several asthma attacks. She has been taking theophylline 600 $\mathrm{mg} \cdot$ day $^{-1}$ and inhaled fenoterol $1.2 \mathrm{mg} \cdot \mathrm{day}^{-1}$, but had discontinued the prescribed corticosteroid for inhalation. Whenever asthmatic attacks became severe she took $4 \mathrm{mg}$ prednisone for a couple of days. Her lung function demonstrated mild airway obstruction. The serum IgE level was $168 \mathrm{IU} \cdot \mathrm{mL}^{-1}$. A radioallergosorbent test revealed specific antibodies to a variety of grass, pollens and dust mites; antibodies against Alternaria alternata were not found. Her 3-yr-old daughter was in good health and without mental deficit.

The mechanism governing the effect of plasma exchange in bronchial asthma remains to be elucidated. Removal of circulating specific IgE antibodies may be an attractive theory $[3,4]$. As with the patients of GARTMANN et al. [1] and BAMBAUER et al. [2], serum IgE levels in the present case decreased following plasma exchange, but increased shortly thereafter without causing a relapse. Thus, it seems highly unlikely that IgE removal was responsible for the overt clinical improvement in these patients. Referring to the work of Fraser et al. [5], MiLler [6] suggested that removal of autoantibodies to $\beta$-adrenergic receptors may be a good explanation for the therapeutic effects of plasma exchange, but to date definite proof is lacking. In the present case report, plasma exchange eliminated approximately $50 \%$ of the measured complement factors and immunoglobulins (table 1), in accordance with calculations on IgE removal made by BAMBAUER et al. [2]. In the present case, it cannot, however, be ruled out entirely that factors other than plasma exchange alone, such as heparin administration, spontaneous relief of bronchospasm or a delayed response to corticosteroid therapy
Table 1. - Serum complement factors (C3, C4) and immunoglobulins ( $\lg \mathrm{A}, \lg \mathrm{G}, \lg \mathrm{M}, \lg \mathrm{E})$ before and after plasma exchange

\begin{tabular}{lcccc}
\hline & $\begin{array}{c}\text { Before } \\
\text { TPE }\end{array}$ & $\begin{array}{c}\text { After } \\
\text { TPE1 }\end{array}$ & $\begin{array}{c}\text { After } \\
\text { TPE2 }\end{array}$ & $\begin{array}{c}\text { After } \\
\text { TPE3 }\end{array}$ \\
\hline C3 & 0.31 & 0.17 & 0.21 & 0.13 \\
C4 & 0.12 & 0.05 & 0.11 & 0.05 \\
IgA & 0.5 & 0.3 & 0.4 & 0.2 \\
IgG & 2.6 & 1.9 & 2.7 & 1.6 \\
IgM & 0.3 & 0.3 & 0.3 & 0.2 \\
IgE & 146 & 98 & 152 & 84 \\
Albumin & 47 & 48 & 44 & 50 \\
\hline
\end{tabular}

All values are in $\mathrm{g} \cdot \mathrm{dL}^{-1}$. TPE: therapeutic plasma exchange.

may account for the observed success in the course of status asthmaticus.

Further work is needed to clarify the mechanisms involved; however, plasma exchange may be considered a treatment option for patients in status asthmaticus, at least when conventional therapies have failed.

\section{Franzen*, H. Günther*, H. Borberg**, K. Wasser- mann*.}

*First and **Third Depts of Medicine, University of Cologne, Germany.

Correspondence: D. Franzen, Berrenraterstr 296, 50937 Cologne, Germany, Fax: 011492214201110.

\section{References}

1. Gartmann J, Grob P, Frey M. Letter to the Editor: Plasmapheresis in severe asthma. Lancet 1978; i: 40.

2. Bambauer R, Jutzler GA, Micka K, Austgen M, Schlimmer P, Trendelenburg F. Drug-resistant bronchial asthma successfully treated with plasma exchange. $J$ Clin Apheresis 1984; 2: 200-205.

3. Burrows B, Martinez FD, Halonen M, Barbee RA, Cline MG. Association of asthma with serum IgE levels and skin-test reactivity to allergens. $N$ Engl J Med 1989; 320: 271-277.

4. Platts-Mills TAE. Mechanism of bronchial reactivity: the role of immunoglobulin E. Am Rev Respir Dis 1992; 145: S44-S47.

5. Fraser CM, Venter JC, Kaliner M. Autonomic abnormalities and autoantibodies to beta-adrenergic receptors. $N$ Engl J Med 1981; 305: 1165-1170.

6. Miller JD. Letter to the Editor. N Engl J Med 1982; 307: 317. 